\section{A Simple Device for the Scintillation Counting of Aqueous Solutions of Calcium-45 and other $\beta$-Emitting Isotopes}

THE methods at present available for counting calcium-45 by conventional liquid scintillation techniques, such as those of Carr and Parsons ${ }^{1}$, Sarnat and Jeffay ${ }^{2}$ and Humphreys ${ }^{3}$, make it possible to count large quantities of low specific activity calcium at efficiencies of 50 per cent or more. However, theso methods are laborious and time. consuming because of the lengthy chemical processing required to produce a calcium salt which will dissolve in the toluene-based scintillator mixture. Methods involving the use of hyamine for the direct solution of tissues or aqueous solutions in toluene ${ }^{4-6}$ are much quicker, but are only capable of counting very small quantities of calcium at lower efficiency; they are also subject to quenching errors. The use of plastic scintillator fibres or beads and anthracene crystals by Steinberg ${ }^{7-9}$ made it possible to count directly colourless aqueous solutions of calcium-45; however, the efficiency, except with anthracene, was low, and the sample and scintillator materials could only be recovered with difficulty. Plastic scintillator systems consisting of a vial ${ }^{10}$ and a flow cell ${ }^{11}$ are capable of counting calcium-45 in aqueous solutions without any corrections for quenching, but their capacity is $1 \mathrm{ml}$. or loss and their efficiency only of the order of 6 per cent.

In many applications it would be useful to be able to count calcium-45 directly in larger volumes of aqueous solutions without quenching corrections, even if at low efficiency. An apparatus designed for this purpose which has proved useful in this laboratory is shown in Fig. 1. It consists of an array of sixty plastic scintillator filaments ( $N E$ 102A, Nuclear Enterprises, Edinburgh), diameter $1 \mathrm{~mm}$, length $4 \mathrm{~cm}$, spaced at intervals of $2 \mathrm{~mm}$ between centres in a 'Perspex' disk. The filaments pierce the disk and their ends are ground and polished flush with its base. The disk is fitted to the bottom of a 'Perspex' cylinder, the whole forming a container of volume $8 \mathrm{ml}$. The "brush" counter, as we have called it, is suitable for counting aqueous, dilute acid or dilute alkali solutions of $\beta$-emitting isotopes in a liquid scintillation counter with a single photo-multiplier. If the filaments are covered with a depth of liquid greater than the range of the $\beta$-particles being counted, it is not necessary to measure the volume of solution counted; the count-rate is proportional to the specific activity of the solution. The counter has the following efficiencies:

$\begin{array}{lc}\quad \text { Isotope } & \text { Efficiency (per cent) } \\ \text { Phosphorus-32 } & 40 \\ \text { Calcium-45 } & 2 \\ \text { Carbon-14 } & 0 \cdot 7\end{array}$

The background count rate is about 1 /sec.

The counter can easily be modified to count samples larger than $8 \mathrm{ml}$. The Ekco $N 664 B$ liquid-scintillation counter used in this laboratory would accommodate a similar counter of maximum volume $20 \mathrm{ml}$. It can also be modified in design to make its construction simpler if only high-energy $\beta$-emitting isotopes are being counted. For example, only six filaments in a brush counter are needed to count phosphorus-32 with an efficiency of 8 per cent.

The brush counter can be compared in its mode of operation and usefulness with the $M 6 H$ Geiger-Müller liquid counting tube. The $M 6 H$ counts phosphorus-32 with an efficiency of about 7 per cent and a background of $0 \cdot 25 / \mathrm{sec}$, but has zero efficiency for both calcium-45

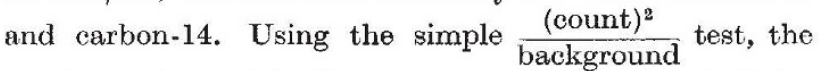
brush counter could achieve comparablo counting statistics for phosphorus-32 in an eighth of the time, and it is also useful for the weak $\beta$-emitting isotopes. The brush counter is therefore more versatile than the $M 6 H$ tube and, compared with liquid scintillation techniques, it has
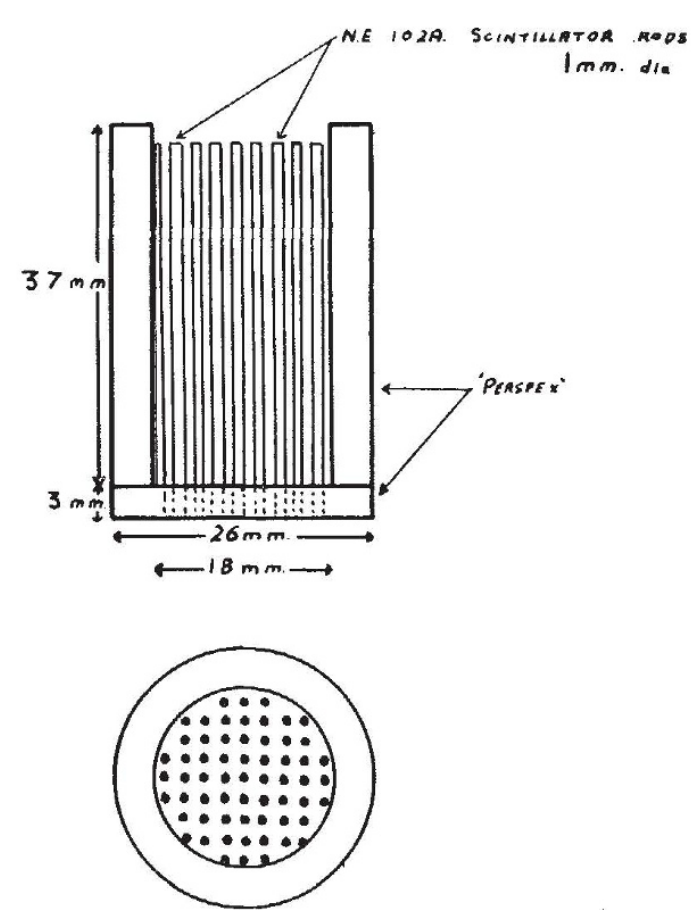

Fig. 1. Side elevation and plan of "brush" counter $(\times 1)$

the advantages of great simplicity of sample preparation and it is not necessary to make corrections for any quenching effects.

B. F. SANSOM

P. J. TAYLOR

Agricultural Research Council,

Institute for Research on Animal Diseases,

Compton, Newbury, Berkshire.

${ }^{1}$ Carr, T. E. F., and Parsons, B. J., Intern. J. App. Rad. Isotopes, 13, 57 (1962).

2 Sarnat, M., and Jeffay, H., Anal. Chem., 34, 643 (1962).

${ }^{3}$ Humphreys, E. R., Intern, J. App. Rad, Isotopes, 16, 345 (1965)

4 Brown, W. O., and Badman, H. G., Biochem. J., 78, 571 (1961).

- Rapkín, E., Bydroxide of Hyamine 10-x, Packard Technical Bulletin (Packard Instruments, La Grange, Illinois, June, 1961).

'Meade, R. C., and Stiglitz, R. A., Intern. J. App. Rad. Isotopes, 13, 11 (1962).

${ }^{7}$ Steinberg, D., Nature, 182, 740 (1958).

" Steinberg, D., Nature, 183, 1253 (1959).

'Steinberg, D., Anal. Biochem., 1, 23 (1960).

${ }^{10}$ Funt, B. L., and Hetherington, A., Science, 129, 1429 (1959).

${ }^{13}$ Schram, E., and Lombaert, R., Anal. Biochem., 3, 68 (1962).

\section{Changes in Loss Tangent of Polythene subjected to Partial Discharge}

IN detemining the resistance of matorials to partial discharges, two distinct types of measurement tend to bc used. In one, the time to breakdown is measured for film or sheet material mounted between rod/plane, needle/ plane or hemisphere/plane electrodes. In the other, relatively large areas of sheet are subjected to discharge between plane/plane electrodes so that degradation after periods of exposure can be measured by following changes in conductivity, loss tangent, mechanical strength, etc. Because these properties change progressively with duration of exposure, the impression is being gained that the changes in the material which cause them are the same as those taking place in the breakdown process. This assumption leads to suggestions like that of Boeck ${ }^{1}$ that impinging electrons become trapped in the material, forming a space charge and enhance the conductivity, the layer becoming ever deeper as fresh charge carriers are supplied. 